\title{
O Direito Internacional Privado e a Família no UMBRAL DO SÉCULO XXI ${ }^{1}$
}

\section{Prof. Dr. Dr. h.c. mult Erik Jayme}

\section{INTRODUÇÃO}

É para mim uma grande honra e um grande prazer retornar a esta Universidade prestigiosa para proferir uma palestra sobre o Direito Internacional Privado. $\mathrm{Na}$ conferência anterior, em 1996, analisei as Convenções internacionais como instrumentos de promoção da integração nas comunidades regionais, como a Comunidade Européia e o Mercosul. ${ }^{2}$

O tempo passa rapidamente. Hoje, no direito eutopeu, as convenções, como instrumento de unificação do direito privado, estão superadas. Foram substituídas, parcialmente, por regulamentos europeus.

O Tratado de Amsterdã introduziu a competência da Comunidade para legislar sobre os conflitos de leis e de jurisdiçōes: Um dos primeiros regulamentos baseado sobre esta nova competência legislativa foi o regulamento nr. $1347 / 2000$ de 29 de maio de 2000 , "relativo à competência, ao reconhecimento e à execução de decisões em matéria matrimonial e da tegulação do poder paternal em relação dos filhos comuns do casal." Este regulamento entrou em vigor em $1^{\circ}$ (primeiro) de março de 2001.

Pata alguns, pode ser surpreendente que a Comunidade (Européia) se ocupe do Direito de Familia, porém, neste regulamento, uma nova base para um direito internacional

1 Esta conferência foi proferida pelo Prof. Erik Jayme, no Rio de Janeiro, no dia 15 de março de 2002, no auditório do B-6 da Puc-Rio. O texto foi elaborado pelo Prof. Jayme para sua exposiçẫo e está no prelo para ser publicado na Revista do Departamento de Direito/Puc-Rio, sob os cuidados da Profa. Dra. Nadia de Araújo. A forma oral foi preservada. Texto gentilmente cedido pela organizadora para publicação nos Cadernos do Programa da Pós-Graduação em Direito-PPGDir./UFRGS, em homenagem ao vitulo de doutor bonoris causa concedido ao autor, texto sen revisão e adição de notas.

2 A versão final da palestra de 1996 foi pubijcado no Brasil. Veja-se JAYME, Brik, "Direito Internacional Privado e Integração" in Integração Jurídica Interamericana, coord. Paulo Borba Casella e Nadia de Araujo, São Paulo, LTr, 1998, pp. $106-116$. 
privado de familia aparece: a livre circulação de pessoas, uma das quatro liberdades fundamentais do Direito Comunitário Europeu.

A liberdade da pessoa de deixar um país e de estabelecer-se em um outro conduz, no âmbito do Direito Internacional privado, ao reconhecimento quase automático do estado familiar desta pessoa. A crítica a este desenvolvimento recente europeu não faltou: fala-se de um estado de família como "mercadoria", que faria parte da livre circulação dos produtos.

Nesta conferência, vamos tratar esta insólita relação do direito de família com a idéia de favorecer a livre circulação de pessoas.

Nosso outro tema será a proteção da identidade culturál da pessoa humana, como contratendência em relação à integração. Os elementos desta identidade são a língua, a religião, a expressão artística e "o estilo de vida", como formulou a Comissão pała a Ptoteção dos Direitos do Homem. A proteção da identidade cultural em tempos pós-modernos privilegia $o$ direito de ser diferente.

No âmbito do direito substancial, o direito pós-moderno exprime-se através da tendência dos legisladores de criarem diferentes institutos alternativos de direito de família, com a conseqüente criação de novos conflitos de leis no umbral deste século. Por exemplo, o direito alemão introduziu, há um ano, a união registrada de pessoas do mesmo sexo. Os Países Baixos preferiram, ao invés, permitir o casamento aos homossexuais. Nesta mesma linha, o direito holandês dispõe hoje de dois institutos jurídicos, o casamento e a união registrada, ambos permitidos a pessoas do mesmo sexo e de sexos diferentes. $O$ direito internacional privado, que pressupõe leis diferentes, torna-se assim importante para a eficácia transfronreiriça destas uniões.

O terceiro tema desta conferência é novo e refere-se à identidade cultural dos sistemas jurídicos e à sua proteção. No tratado da União Européia encontramos no Art. $4^{\circ}$ (quarto) uma regra geral, segundo a qual a União Européia teconhece a identidade nacional dos Estados Membros.

Esta identidade compreende tambérn certos elementos do sistema jurídico nacional e pode ser configurada como um limite à unificação do direito substancial. Poderíamos perguntar qual será o papel do direito internacional privado para a manutenção de um equilibrio entre os sistemas nacionais e o direito comunitário. Além disso, aparece o conflito de sistemas como um conflito de civilizações.

Seguindo este caminho temos, pois, três temas:

1. o direito internacional de familia e a livre circulação de pessoas;

2. a proteção da identidade cultural da pessoa e a sua autonomia para escolher entre institutos jurídicos diferentes em uma sociedade multicultural;

3. o direito internacional privado e a preservação dos elementos culturais dos sistemas nacionais.

\section{I - A Livre Circulação de Pessoas}

Começaremos com a livre circulação de pessoas como liberdade fundamental. O novo regulamento europeu relativo à competência, ao reconhecimento eà execução das decisões em matéria matrimonial é precedido de detalhadas considerações, entre elas o Considerando nr. 8: 
"É oportuno que o presente regulamento preveja medidas coerentes e uniformes que permitam um circulação de pessoas tão ampla quanto possivel. Assim, é necessário aplicá-lo, igualmente, aos nacionais de Estados Terceiros que apresentem um vínculo suficientemente forte ao território de um dos Estados-Membros, em conformidade com os critérios previstos no Regulamento."

A mobilidade e a livre circulação de pessoas aparece, neste regulamento europeu, como um valor fundamental que excede ao objetivo de integração em um mercado comun.

A técnica seguida pelo legislador europeu é o reconhecimento reciptoco, na Europa, dos estados familiares criados nos países da Comunidade. O direito internacional privado é excluído, prevalece $o$ direito processual internacional.

Dispõe o Art. 18 do Regulamento:

"O reconhecimento de uma decisão em matéria de divórcio, separação de pessoas e bens ou anulação do casamento não pode ser recusado em virtude da lei do Estado-Membro requerido não permitir o divórcio, a separação de pessoas e bens ou a anulação do casamento com base nos mesmos fatos."

As diferenças entre as leis aplicáveis não mais importam. O princípio do reconhecimento recíproco substitui, pois, as normas de conflitos. Para estabelecer a competência basta a residência habitual do requerente, se este estiver aí residindo há pelo menos um ano imediaramente antes do pedido. Este periodo de tempo será reduzido a seis (6) meses, caso o requerente seja nacional do Estado-Membro em questão.

Como conseqüência, uma pessoa que deixa a paz do lar familiar pode, em breve tempo, alterar as suas relações familiares e obter a dissolução do casamento, com reconhecimento certo em toda a Europa.

Favorece-se desta maneira o cônjuge "mais móvel", a recordar a ária "La donna é mobile" da Ópera "Rigoletto" de Verdi, o que parece pouco compativel com o princípio da estabilidade da família; constitui um primeiro passo para uma regulamentação justa dos confliros de leis em matéria matrimonial. Mencione-se também que já existe um primeiro projeto para um regulamento de conflitos de leis em matéria de divórcio.

Fato é que, no umbral do século XXI, aparece, como fundamento do direito de familia internacional, a liberdade individual de livre circulação de pessoas, uma idéia nova, mas com criticáveis conseqüências. Esta nova tendência conduz à questão de uma auronomia mais ampla de escolha da lei aplicável no âmbito do direito de família. Já, indiretamente, através da escolha do foro competente, o cônjuge requerente pode influenciar o direito aplicável.

O Kammergerichr de Berlim foi confrontado com uma petição de divórcio de um casal, que vivia na Espanha. O homem era de nacionalidade austríaca, a mulher, de nacionalidade alemã. Segundo o direito internacional privado alemão, aplica-se ao caso de divórcio de um casal de nacionalidade diferente, a lei da residência habitual comum. Para evitar a aplicação do direito espanhol, pouco familiar a um casal austríaco-alemão, o casal escolheu, em uma declaração de vontade de forma solene, o direito alemão para regular o seu divórcio. Os juizes de Berlim decidiram que a escolla da lei aplicável limitada ao divórcio não seria admissível no direito alemão, o qual permite a escollha da lei aplicável somente ao 
regime de bens e aos efeitos gerais do casamento. Esta interpretação estreita e literal das normas de conflito foi criticada pela doutrina.

O caso demonstrou bem as vantagens de una certa autonomia da vontade, mesmo no âmbito do diteito de família e pode ser considetada como a futura melhor solução para o direito eutopen.

\section{II - Identidade Cultural da Pessoa}

A contratendência, em respotas às necessidades de uma integração sempre mais intensa na Europa, concerne a proteção da identidade cultural através do direito internacional privado. Na prática quotidiana, observamos uma crescente importância das regras de direito de familia de origem religiosa.

Há quatro possibilidades de um juiz ter em conta tais leis religiosas:

1) O direito internacional privado indica aplicável a lei de um Estado que, em seu direito de fanília, observa as leis de comunidades religiosas, como, por exemplo, o direito islâmico;

2) No âmbito do direito substancial, as cláusulas gerais, como a observância do bemestar da criança, abrem o caminho para o direito religioso, se este direito religioso corresponde à identidade cultutal da criança;

3) A ordem pública pode ser concretizada por normas religiosas, se estas fazem parte do exercício de liberdade religiosa como direito humano.

4) Finalmente, podemos mencionar a recepção dos institutos jurídicos religiosos no direito civil substancial.

Daí surgem conflitos novos. Vou dar alguns exemplos da prática jurídica alemã.

A Relação de Karlstuhe ocupou-se de um pedido de um casal para adotar uma criança marroquina. Os pais adotivos, que viviam na Alemanha, eram ao tempo do casamento ambos marroquinos, mas o cônjuge varâo tinha obtido a nacionalidade alemã. A lei aplicável a esta adoção era o direito marroquino, que proíbe a adoção, seguindo as regras do Alcorão. Os juizes alemães normalmente, se a familia vive na Alemanha, excluem o direito marroquino, pronunciando a adoção para proteger o bem-estar da criança, baseando esta decisão na ordem pública alemã. A Relação de Karlsruhe, ao contrário, teve em conta, no âmbito da ordem pública, a identidade cultural da criança, sugerindo ao juiz de primeira instância, como solução, a admissibilidade da "kafala", instituto jurídico do direito islâmico equivalente a uma colhimento familiar com efeitos menores do que uma adoção plena do direito alemão. O Tribunal citou, nesta decisão, a Convenção da ONU sobre os Direitos da Criança de 1989.

Neste caso, a ordem pública revela um "double coding": os direitos humanos configurados como valores universais e internacionais concretizam a ordem pública nacional. No centro, está a criança e sua identjdade cultural.

Esta nova filosofia inspirou o legislador espanhol a introduzir, recentemente, no Código Civil Espanhol, vários tipos de acolhimento familiar, entre os quais um semelhante 
à "kafalah", para o juiz escolher o instituto jurídico mais apto para proteger a identidade cultural da criança.

No mesmo contexto, poderíamos mencionar a nova lei alemã de 5 de novembro de 2001 sobre os efeitos da adoção pronunciada segundo o direito estrangeiro. Esta lei tem em conta o fato já notmal de um casal alemão adotar uma criança em um país estrangeiro, muitas vezes na América Latina. Esta lei permite aos pais adotivos escolher, na Alemanha, entre um processo que conduza ao reconhecimento da sentença de adoção estrangeira declarando seus efeitos, segundo o direito estrangeiro, e uma petição visando transformar a adoção estrangeira em adoção plena do direito alemão. Desta maneira, o legislador alemão reconhece, indiretamente, a adoção simples estrangeira, desconhecida no direito substancial alemão.

A transformação de uma adoção estrangeira em uma adoção de direito alemão é admitida somente se os consentimentos necessários a esta adoção subsistem. Neste âmbito, o legislador alemão invoca também a norma geral da ordem pública alemã. Esta lei alemã apresenta alguns fenômenos do direito pós-moderno: uma pluralidade de métodos além das categorias consolidadas, um processo que combina elementos de direito processual e de direito substancial e uma escolha possível entre os diversos institutos jurídicos pelos interessados.

A aplicação do direito religioso, nos demais casos, torna-se mais dificil. O Kammergericht de Berlim recusou o divórcio a um casal de nacionalidade israelense e de religião judaica, apesar de o direito internacional privado alemão temeter à lei da nacionalidade, deixando assim o casal sem acesso aos Tribunais de seu domicílio. Os juízes fundaram a sua decisão no argumento de que, um tribunal estatal não seria competente para aplicar regras religiosas.

De acordo com o direito de Israel, o divórcio consiste em um negócio jurídico privado dos cônjuges precedido de um processo controlado por um tribunal rabínico.

Em minha opinião, o Tribunal alemão pode pronunciar o divórcio em uma sentença, após ter obtido a informação do tribunal religioso de que as regras religiosas foram observadas pelo casal.

O outro problema recente conceme aos diferentes estilos de vida e os institutos jurídicos altemativos.

Um primeito caso, na Alemanha, envolve um holandês, unido em matrimônio celebrado, nos Páses Baixos, com uma pessoa do mesmo sexo. Os dois homens estabeleceram seu domicílio na Alemanha, onde é admitida, para pessoas do mesmo sexo, somente a união registrada, mas não o matrimônio. De outro lado, o legislador alemão introduziu, no ano passado, uma nova regra de conflito, segundo a qual a lei do país de registro é aplicável a uma união de pessoas do mesmo sexo.

Surgem aqui os problemas conhecidos da qualificação de um instituto jurídico estrangeiro desconhecido no ordenamento jurídico nacional. Há duas soluções, ou aplica-se analogamente a lei aplicável ao matrimônio e chega-se à lei nacional das pessoas em questão, ou a lei aplicável às uniões registradas, isto é, a lci do país de registro. Em ambos os casos é aplicável o direito dos Países Baixos; o qual admite o matrimônio de pessoas homossexuais. 
Continuamos com os outros elementos da identidade cultural e a sua importância para o direito internacional privado de família.

Gostaria de falar de um caso recente decidido pelo Tribunal de Freiburg. Tratavase de um divórcio de cônjuges com dupla nacionalidade idêntica - francesa e libanesaque viviam na Alemanha. Para determinar, quanto ao princípio da nacionalidade, se os cônjuges teriam a mesma nacionalidade, o juiz procedeu a uma interessante análise da efetividade das nacionalidades, chegando à conclusão de que a mulher era francesa e o varão, ao invés, era libanês. O varão tinha adquirido a nacionalidade francesa pelo casamento, falava quatro línguas e a língua francesa tinha uma importância menor em relação à língua árabe. A mulher era de origem francesa, mas tinha vivido durante a infância no Líbano, onde conheceu o seu marido e onde o casal viveu os primeiros anos após a celebração do casamento. As relações atuais da mulher com o Líbano eram fracas. Ela preferiu a França para viajar em suas férías.

Tratando-se, segundo a opinião do juiz, de um casal de nacionalidade diferente aos fins do direito internacional privado, foi aplicado o direito alemão, como lei da última residência comum do casal.

A decisão pode ser criticada. O juiz não teve em conta o fato de que o direito alemão, na falta de uma nacionalidade comum atual, remete à última nacionalidade comum, logo, à nacionalidade libanesa, da mesma forma desconsiderou o fato do casal ter vivido no Líbano durante os primeiros anos após o casamento e tendo sido neste pais o primeiro domicilio conjugal.

De outro lado, a decisão bem demonstra que a identidade cultural da pessoa serve para concretizar a efetividade da nacionalidade, nos casos envolvendo pessoas com dupla nacionalidade.

\section{III - A Preservação dos Elementos Culturais Nacionais}

Chegamos ao terceiro tema, o direito internacional privado e a preservação dos elementos culturais dos sistemas nacionais.

Trara-se de um tema novo. No âmbito da unificação do direito substancial nas coniunidades regionais surge a questão se a unificação deveria respeitar certos limites postos pela identidade cultural dos sistemas jurídicos nacionais dos Estados-Membros.

Além disso, podemos perguntar qual é o papel do direito internacional privado nos conflitos de civilização que determinam a política mundial de nosso tempo.

Devemos constatar que o direito internacional privado oferece sua própria idéia de Justiça: o tratamento igual das leis diferentes, sempre que o caso apresente uma conexão estreira com o respectivo país. Desta maneira, abre o diálogo intercultural entre sistemas diversos.

Importa no direito de família mencionar que os indivíduos têm um interesse forte no reconhecimento universal de suas relações jurídicas. A famillia não conhece fronteiras políticas.

O papel do direito internacional privado como um ramo de Direito que estimula o diálogo entre as culturas aparece claramente em uma sentença da Corte Suprema da Bavária 
de 28 de novembro de 2001 . Um homem e uma mulher de nacionalidade iraniana viviam na Alemanha, o homem como refugiado reconhecido como tal pela Convenção da ONU e a mulher como candidata a asilo. Esperavam um filho. Celebraram o casamento segundo as leis iranianas, no Irã, através de um procurador. O filho nasceu e o oficial do cartório deveria decidir sobre o registro do filho como oriundo ou não do casamento. Esta forma de celebração do casamento não é admitida na Alemanha; a lei iraniana permite mesmo a escolha do cônjuge pelo procurador. Tratava-se de um conflito de civilizações.

A lei aplicável para a substância do casamento foi a lei alemã, como a lei de domicilio de um refugiado; a lei aplicável à forma do casamento foi a lei do Irã . Incumbia decidir se na questão da admissibilidade de um verdadeiro procurador trara-se de substância do ato e não de forma.

De outro lado, no caso concreto ambos os interessados, antes da procuração, já tinham formado um livre consenso visando o casamento, consenso este que permanece a base do sistema ocidental para fundar uma família. A corte decidiu que o matrimônio foi válido, qualificando o caso concreto como pertencente à forma dos atos. Desta maneira, regulado pela lei do Irã. Teve em conta, também, a nacionalidade iraniana de ambos os cônjuges $\mathrm{e} o$ interesse do filho de ser filho legítimo.

Como se vê, o direito internacional privado oferece um método e um processo discursivo para dialogar entre as culturas diversas: um instrumento sempre mais importante para chegar a soluções pacíficas.

\section{CONCLUSÃO}

No umbral do século XXI, a família mudou, porém, o direito internacional privado permanece sempre um instrumento eficaz e justo para indicar a lei aplicável aos casos multiconectados e multiculturais. 